\title{
A FRAMEWORK FOR CREATING VALUE FROM FLEET DATA AT ECOSYSTEM LEVEL
}

\author{
Sini-Kaisu KINNUNEN ${ }^{1}$, Jyri HANSKI ${ }^{2}$, Salla MARTTONEN-AROLA ${ }^{1}$, Timo KÄRRI ${ }^{1}$ \\ ${ }^{1}$ Lappeenranta University of Technology \\ ${ }^{2}$ VTT Technical Research Centre of Finland Ltd Tampere
}

\begin{abstract}
:
As companies have recently gotten more interested in utilizing the increasingly gathered data and realizing the potential of data analysis, the ability to upgrade data into value for business has been recognized as an advantage. Companies gain competitive advantage if they are able to benefit from the fleet data that is produced both in and outside the boundaries of the company. Benefits of fleet management are based on the possibility to have access to the massive amounts of asset data that can then be utilized e.g. to gain cost savings and to develop products and services. The ambition of the companies is to create value from fleet data but this requires that different actors in ecosystem are working together for a common goal - to get the most value out of fleet data for the ecosystem. In order that this could be possible, we need a framework to meet the requirements of the fleet life-cycle data utilization. This means that the different actors in the ecosystem need to understand their role in the fleet data refining process in order to promote the value creation from fleet data. The objective of this paper is to develop a framework for knowledge management in order to create value from fleet data in ecosystems. As a result, we present a conceptual framework which helps companies to develop their asset management practices related to the fleet of assets.
\end{abstract}

Key words: fleet data, ecosystem, framework, value, data refining, asset management

\section{INTRODUCTION}

Assets produced by an original equipment manufacturer (OEM) are often distributed to many customers and different locations. From the manufacturer's point of view the products or assets of fleet are often scattered to wide range of companies. Thus, the data related to fleet of assets are fragmented in an industrial ecosystem where e.g. a manufacturer has product data, an asset owner has process data and a service provider has the service data related to a certain fleet of assets. This fragmented data concerning the fleet is hindering the full exploitation of fleet data in the decision making and also in the service development.

Recently, the aim among industries has been to develop data processes in order to benefit from collected data in asset management decision making. Manufacturers are also willing to increasingly provide knowledge-based services alongside the products. Technologies have partly facilitated this movement but there are still challenges especially related to data sharing between companies in industrial network but the challenge is also to share data effectively even inside an organization. As the fleet of assets and the data related to the assets are often fragmented in different companies no one has the access to all the data concerning the fleet. In order to be able to generate fleet data based services these challenges need to be considered. The literature presents general frameworks to upgrade data into knowledge but they are lacking the perspective of company networks or ecosystems combined with the fleet manage- ment point of view. Therefore, there is a need for a framework which combines data refining process with ecosystem and fleet management perspectives. Thus, the purpose of this paper is to develop and illustrate the role of ecosystem when creating value from fleet data. The aim of this paper can be concluded into the following research question:

How can the process from fleet data to decisions in an ecosystem be illustrated?

Research question is answered by developing framework to meet the requirements of fleet data utilization in order that the value creation in ecosystem could be possible. By reviewing literature it has been acknowledged that the traditional knowledge management frameworks do not consider the development of modern ecosystem concept and the special characteristics of fleet data management. Thus, the research is conducted by developing analytically the existing data management and knowledge management frameworks. As a result a conceptual framework is developed and the results are discussed.

\section{LITERATURE}

\section{Ecosystems in Literature}

The developments in business environments are resulting in companies and other organizations networking in increasing pace. As the significance of networking has increased, companies are trying to develop powerful partnerships in order to fare in the competition between networks. 
This increased interest in the subject can be noticed from the plentiful and multifaceted research conducted in the field. The subject is discussed with different terms such as industrial networks and value chains that often appear in the literature. In addition, the term of ecosystem has been used in business context as well as by several authors $[1,2$, $3,4,5]$.

The term of ecosystem is used to represent the network and especially to highlight the interdependencies between network partners in order to achieve mutual effectiveness and survival [6]. The term ecosystem is also utilized to symbolize the sustainability and sustainable development aspects that are aimed in ecosystem level cooperation [1, 7]. There are different kinds of views to determine ecosystems and for example the terms of business ecosystem, industrial ecosystem, innovation ecosystem, and information technology (IT) ecosystem or digital ecosystem are presented in the literature. Peltoniemi and Vuori [8] have reviewed the different views of ecosystem in detail. For instance Moore [9] defines the business ecosystem as "an economic community supported by a foundation of interacting organizations and individuals - the organisms of the business world". IT ecosystem or digital ecosystem is founded on a platform where data and applications create the basis for the value creation in the ecosystem [10]. Industrial ecosystem can be defined as "a regional collection of industrial actors that cooperate in each other's waste material and waste energy utilization" [4]. Therefore industrial ecosystem can be regarded as an environmental ecosystem with the circle of material, energy and information. Despite the accurate term, the ecosystem can be concluded to refer to an interconnected population of organizations which can be small companies, large corporations, universities, research centers, public sector organizations, and other actors who influence the system [8].

As the definition for the ecosystem does not appear to be fully unambiguous and none of the definitions meets the requirements that we have when considering the ecosystem in the fleet context, we are regarding the ecosystem as the combination of three different ecosystem concepts: business ecosystem, IT ecosystem, and industrial ecosystem. In the Figure 1 the relation between these three definitions is presented. We define the value ecosystem around the fleet to contain the properties of business ecosystem, such as strong interdependencies between the actors of ecosystem and the aim of mutual value creation. The concept of industrial ecosystem highlights the importance of sustainability aspects which are significant as well for the fleet value ecosystem. The sustainability refers to the point that the ecosystem functions in a way where each actor is benefitting and no one's position in the ecosystem is indefensible. As the fleet data is the starting point for the value ecosystem around the fleet, the features of IT ecosystem, such as data and platform-centered approaches, are essential. Consequently, we define the value ecosystem around the fleet to be a combination of three subsystems including features of business ecosystem, IT ecosystem and industrial ecosystem. The ecosystem is formed around the fleet and basing on fleet data platform or corresponding information technology solutions. With the aid of information technological solutions a group of interconnected organizations are benefitting from fleet data and creating value in a sustainable way.

Ecosystem around the fleet is formed by several different actors which have different roles in the ecosystem in- teraction. Companies in the ecosystem may have roles such as equipment provider, customer or asset owner, and various service providers who all have certain relation to the fleet of assets and are involved in the fleet data based value creation. Especially, when it is a question about data refining in the ecosystem, the role of IT service providers is emphasized. Different actors in ecosystem are complementing the whole ecosystem and they have their role in the data refining process in order to create value from fleet data. The aim of value ecosystem around the fleet is the value creation for the whole ecosystem. The functionality of ecosystem is based on mutual trust and benefitting all the actors of ecosystem [11]. However, this characterization is representing the ideal ecosystem, and the common value creation and benefitting all the actors in ecosystem are more like the ambition than reality. There is still plenty to do before this kind of ecosystem could function as it is supposed and before the companies can create value for ecosystem around a fleet.

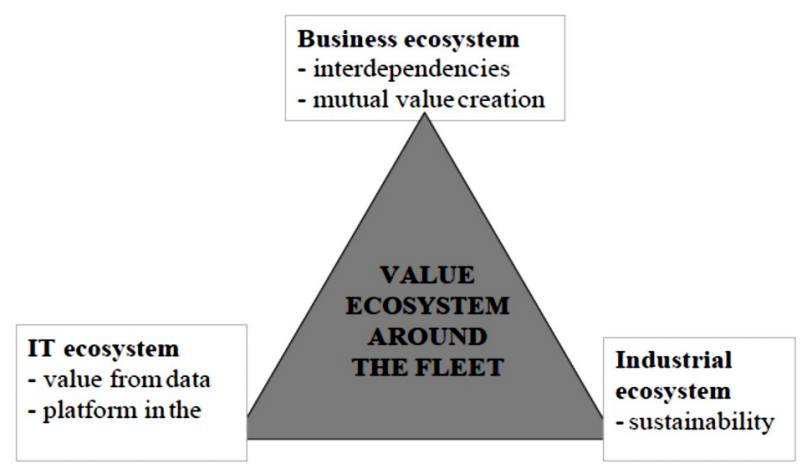

Fig. 1 The concept of value ecosystem around the fleet as a combination of different definitions of ecosystem

In order to get closer to the ambition state, the first step is to understand the roles of actors in ecosystem around a fleet. As the ecosystems and their interdependencies are often complex, this sets requirements for data acquisition and data sharing as well as for upgrading the data into valuable business knowledge for decision makers. These issues become relevant if companies in the ecosystems are willing to benefit from fleet-wide data and as the data can be owned by different companies they need to understand their role in the fleet data refining process. Figure 2 is presenting simply the roles of ecosystem actors in fleet data generation.

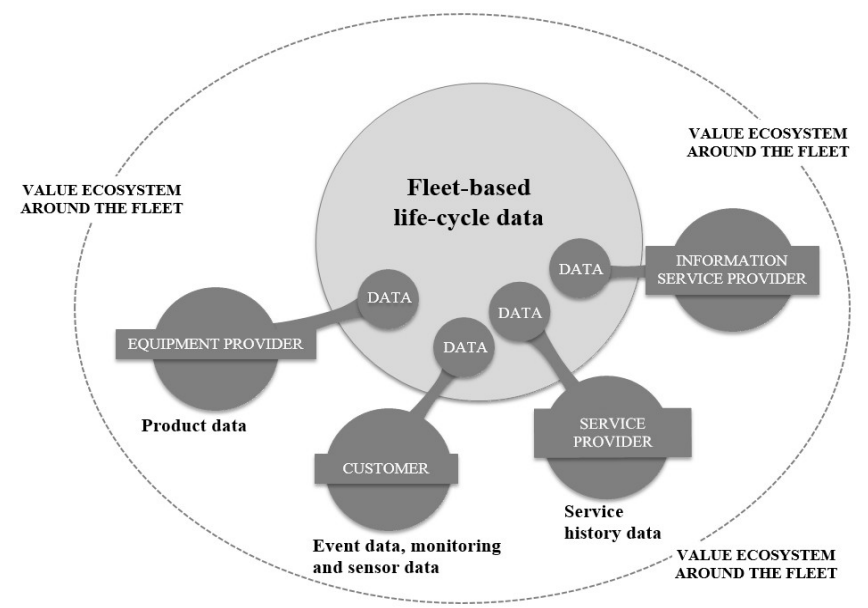

Fig. 2 Ecosystem around the fleet - the impact of ecosystem actors on fleet data 
Information and Knowledge Management Models for Ecosystems to Manage Fleet Data

In the literature, general models for data management and data refining process are presented often in the fields of information and knowledge management research. General models and frameworks for knowledge management are presented by noted researches e.g. Nonaka and Takeuchi [12] as well as Davenport and Prusak [13]. When considering the process from data to knowledge the classifications for the data refining levels, also known as knowledge hierarchy, often appears in literature [14]. Knowledge hierarchy divides the levels of data, information, knowledge and wisdom. Data is regarded as unprocessed data or symbols, information is regarded as processed data that can be used, knowledge is refined from data and information, and wisdom refers to understanding. This kind of classification is essential when discussing the data to decision process.

Although the literature presents a large amount of models and frameworks for information and knowledge management, there is still a need for more specific frameworks in different business contexts and different levels of business. In other words, there are needs for the models for information management related to just a certain process, for the models related to information management at organizational level, and when the business networks and ecosystems are increasing, there is a need also for ecosystem level information models. Within the research program Service Solutions for Fleet management [15] researchers such as Kunttu et al. [16] have applied the data models to the knowledge-intensive service development by creating a framework (Figure 3) for information management in a single firm case. They present the framework for data-todecision where the manufacturer manages the information flows from external and internal sources. The framework consists of six phases: data collection, data pre- treatment, descriptive data analysis, data modelling, soft and hard data combination and the comparison of decision options. The sequential phases result in the various levels of understanding to make the data useful for decision-making i.e. data, information, knowledge and wisdom [16].

When starting to develop the framework for fleet data management at ecosystem level, the data to decision framework presented by Kunttu et al. [16] is a good starting point. The framework presented by Kunttu et al. [16] illustrates the data refining process from data to decisions and the framework functions as a tool to develop knowledgeintensive services. However, the framework considers that the process is handled by a single company but it does not consider that the process from data to decisions is not always mastered by a single company. The process from data collection to decision making may be affected by several companies in ecosystem. Especially, when we are considering fleet-wide data, even the phase of data collection is executed by multiple companies as was presented in Figure 2. In addition, data pre-treatment and other data processing is often provided by information service providers. Another important aspect which is related to the ecosystem view is the value creation through data refining process. There is a need to clarify the roles of companies in the ecosystem around the fleet when creating value from fleetwide data. Thus, who is benefitting or should we maximize the value for the whole ecosystem? The understanding of the roles in ecosystem is a step forward to create new business as well as sharing benefits and risks in ecosystems.
Framework (Figure 3) could be developed further in a way which takes the role of collaboration in the ecosystem into account and considers challenges related to costs, benefits and information sharing.

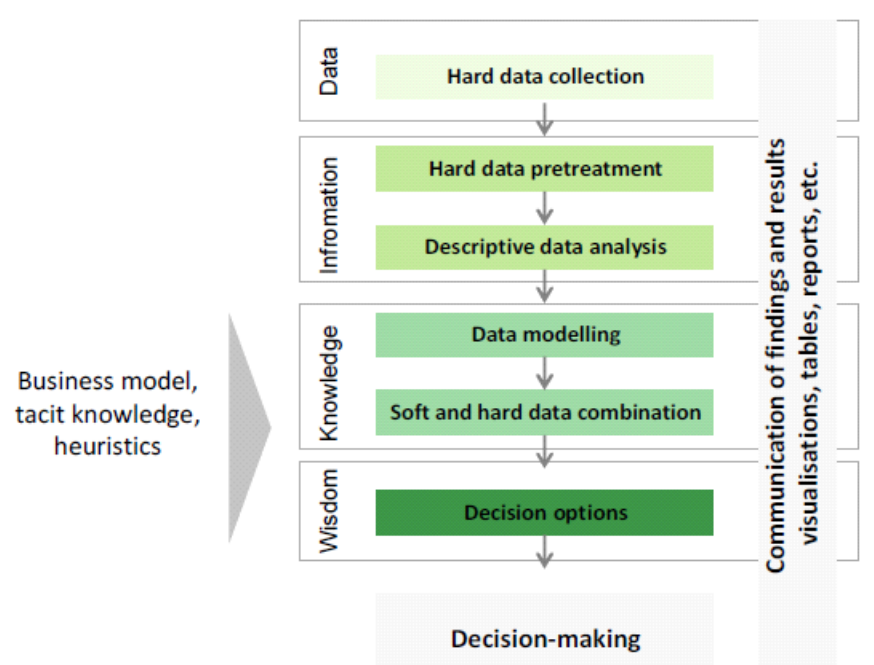

Fig. 3 Framework for information management and the relationship of data, information, knowledge and wisdom Source: [36].

\section{FRAMEWORK FOR CREATING VALUE FROM FLEET DATA AT ECOSYSTEM LEVEL}

Existing knowledge management models which generally are known in information management context have been the basis for the development of the new framework in this paper. The general information and knowledge management frameworks presented in literature have now been integrated with loT, ecosystem and fleet management viewpoints as a part of ongoing research program. Prior research, the research work during the research program and the collaboration with companies within the program, including workshops, have been the basis for the development work of the framework. Data to decisions framework developed by Kunttu et al. [16] is also a result of the research program and there are still possibilities to develop the ideas of data to business knowledge process further. Some ideas for further development were discussed in section 2.2.

In Figure 4, we are presenting the new framework which has influences also from the data-to-decision framework developed by Kunttu et al. [16]. The main need to develop the framework further is to clarify the roles of actors in data to decision process at ecosystem level. In other words, to clarify the process of how the fleet data can be turned into value in ecosystem. As there are several actors involved in the ecosystem, it is vital to be able to create value for the ecosystem as an entity but to create value for each actor in ecosystem as well. The actors in the ecosystem have different roles in the data refining process and thus in value creation. Figure 4 describes a swim lane flowchart where each actor has their own lanes describing their participation in the data to decision process. The black arrows are representing information flows between data refining phases and actors. It can be noticed that some of the actors have smaller roles in the process while the others might have important role in multiple phases in the process. In addition, in the top part of the figure, the stacked bars describe how the costs and benefits are generated through the process. Costs and benefits can be ob- 
served at actor level, as each actor has their own green and orange colors, and at the ecosystem level when the total costs and benefits can be observed. The value for ecosystem can be evaluated as the difference or ratio between discounted benefits and costs.

Figure 4 is representing an example how the process from data to decision in the ecosystem around fleet can be illustrated. However, the situation is often that each actor is managing the process from data collection to decisions by themselves inside the boundaries of company, i.e. companies are staying in their own swim lanes. However, this may lead to the situation where all the data is not available as fleet data is often fragmented to several actors in ecosystem. Therefore, it would be reasonable if the whole ecosystem was pursuing to benefit from the fleet data gathered by different actors. However, this requires that the actors of ecosystem are willing to cross the boundaries of their swim lanes and consider the roles of actors in data refining process. The mobility of data between actors in ecosystem is essential for fleet data utilization at ecosystem level.

Naturally, the whole process and each phase from data collection to decision making are not the core business for all the actors. Some actors might be specialized to some phases while others are mastering the other phases. It could be beneficial if the roles for different data refining phases were considered based on the core competencies of companies. This requires that the current situation in ecosystem can be illustrated and then developed and managed in order to create more value from fleet data for the eco- system. Figure 4 is representing a suggestion for the data refining process in ecosystem where data are shared in ecosystem and each actor has their own roles in the process. For example, service provider I is taking care of data pretreatment collected by multiple actors and other actors are utilizing this data. It can be noticed as well that equipment provider and service provider II are providing analysis and models to support their own businesses but to support the customer's business as well. The costs and benefits are generated through the process for each actor and for the whole ecosystem. For example, different phases are causing different amount costs to each actor and the amounts of benefits are varying as well. Inspecting the value aspect is important as none of the actors should be in an indefensible position while others are gaining all the value. It is not beneficial either for the ecosystem. The ambition of ecosystem is to create value for each actor in ecosystem but for the whole ecosystem as well.

Figure 4 is a simplified description of an ecosystem. The purpose of the framework is to demonstrate how the actors could cross the boundaries of their own company and utilize the fleet data collected by other actors in order to create more value for the whole ecosystem. There could be more actors in real ecosystem and the situation is often more complex. The framework can be applied to different cases and the illustration needs to be done based on the case. Based on the illustration, the process from fleet data to decision making can be developed and managed at ecosystem level.

Value:

$\mathrm{B}-\mathrm{C}$ or $\mathrm{B} / \mathrm{C}$
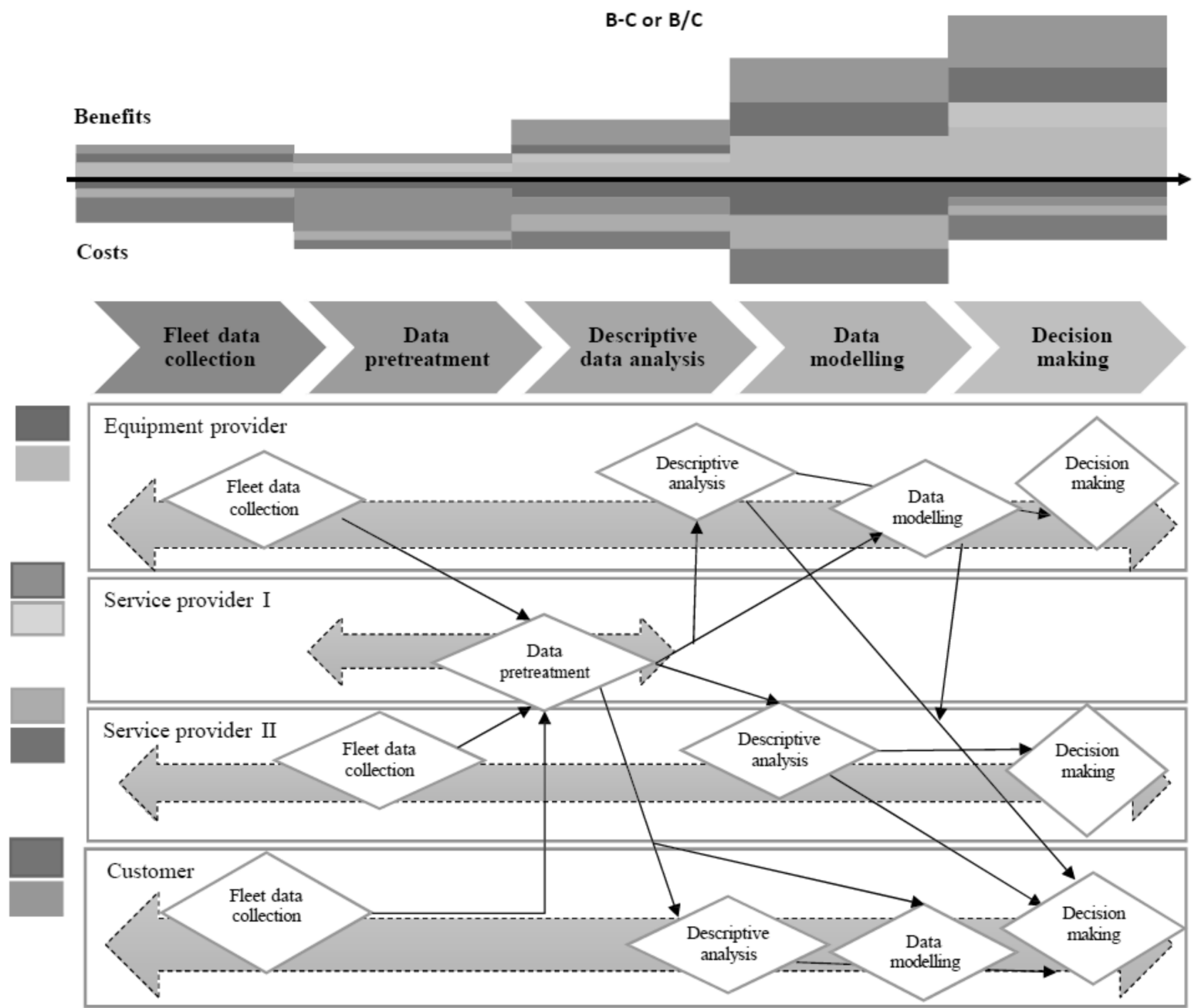


\section{DISCUSSION AND CONCLUSION}

The potential to utilize fleet-wide data, which have been fragmented inside and outside organization, has been acknowledged and the need for understanding how to better manage the fleet data is recognized. This brings into discussion the data utilization at ecosystem level where the ecosystem is founded on the data of asset fleets. The value ecosystem around the fleet is founded on fleet data which highlights the IT ecosystem perspectives, but at the same time the interdependencies and value creation of business ecosystem definition are present, as well as sustainability considerations from industrial ecosystem approach are essential. Value from fleet data should be created in a way which benefits all the actors and the ecosystem as a whole. To respond this and the research question, a new framework is developed as a result of this paper. The framework is suggesting that the phases from fleet data collection to decision making could be realized by utilizing the core competencies of each actor and sharing the data between the actors in order to create value for each actor and for the whole ecosystem.

The framework can be used in many managerial purposes such as a tool of service development but also as a tool in fleet management related to asset management and as a help in information system descriptions where the information management model combined with ecosystem can be valuable. The framework can be used as a tool to evaluate the ecosystem around a fleet and the roles of actors in the data refining process. Companies can model their ecosystem around the fleet with the aid of the framework, and develop the data to decision process at ecosystem level in order to increase value creation. Companies can analyze the ecosystem and data refining process in order to recognize if there are overlapping processes which could then be improved by clarifying the roles of each actor. In addition, as the framework considers also value creation as the difference or ratio between discounted benefits and costs, it can also be used as a tool to develop the performance management of ecosystem.

The presented framework needs to be developed further and it needs to be tested with case ecosystem. The further research is focusing on the calculation of the costs and benefits of actors and on modelling the value of fleet data for ecosystem.

\section{ACKNOWLEDGMENT}

The authors gratefully acknowledge DIMECC

(Digital, Internet, Materials \& Engineering Co-Creation)

for organizing Service Solutions for Fleet Management program (S4Fleet), the Finnish Funding Agency

for Technology and Innovation for funding the program and the companies involved in the research.

\section{M.Sc. Sini-Kaisu Kinnunen, D.Sc. Salla Marttonen-Arola, Prof. Timo Kärri}

School of Business and Management, Lappeenranta University of Technology Lappeenranta Skinnarilankatu 34, 53850 Lappeenranta, FINLAND

e-mail: sini-kaisu.kinnunen@lut.fi salla.marttonen-arola@lut.fi timo.karri@lut.fi

\section{M.Sc. Jyri Hanski}

VTT Technical Research Centre of Finland Ltd Tampere Tekniikankatu 1, 33720 Tampere, FINLAND

e-mail: jyri.hanski@vtt.fi

\section{REFERENCES}

[1] Y. Geng and R. Côté, "Diversity in industrial ecosystems", International Journal of Sustainable Development and World Ecology, vol. 14, no. 4, pp. 329-335, 2007.

[2] G.K.S. Gossain, "Reinventing value: The new business ecosystem", Strategy \& Leadership, vol. 26, no. 5, pp. 28-33, 1998.

[3] M. Iansiti and R. Levien, "Strategy as Ecology", Harvard Business Review, vol. 82, no. 3, pp. 68-78, 2004.

[4] J. Korhonen, "Four ecosystem principles for an industrial ecosystem", Journal of Cleaner Production, vol. 9, no. 3, pp. 253-259, 2001.

[5] J.F. Moore, "Predators and Prey: The New Ecology of Competition", Harvard Business Review, vol. 71, no. 3, pp. 75-83, 1993.

[6] M. lansiti and R. Levien, The Keystone Advantage: What the New Dynamics of Business Ecosystems Mean for Strategy, Innovation and Sustainability. Harvard (MA): Harvard University Press, 2004.

[7] W.S. Ashton, "The Structure, Function, and Evolution of a Regional Industrial Ecosystem", Journal of Industrial Ecology, vol. 13, no. 2, pp. 228-246, 2009.

[8] M. Peltoniemi and E. Vuori, "Business ecosystem as the new approach to complex adaptive business environments", in Proc. of eBusiness Research Forum, 2008, pp. 267-281.

[9] J.F. Moore, The Death of Competition: Leadership and Strategy in the Age of Business Ecosystems. New York (NY): Harper Business, 1996.

[10] K. Karhu, A. Botero, S. Vihavainen, T. Tang and M. Hämäläinen, "A Digital Ecosystem for Co-Creating Business with People", Journal of Emerging Technologies in Web Intelligence, vol. 3, no. 3, pp. 197-205, 2011.

[11] M. Heikkilä and L. Kuivaniemi, "Ecosystem Under Construction: An Action Research Study on Entrepreneurship in a Business Ecosystem", Technology Innovation Management Review, vol. 2, no. 6, pp. 18-24, 2012.

[12] I. Nonaka and $\mathrm{H}$. Takeuchi, The knowledge-creating company: How Japanese companies create the $d y-$ namics of innovation. Oxford: Oxford University Press, 1995.

[13] T.H. Davenport and L. Prusak, Working knowledge: How organizations manage what they know. Brighton (MA): Harvard Business Press, 1998.

[14] J. Rowley, "The wisdom hierarchy: Representation of the DIKW hierarchy", Journal of Information Science, vol. 33, no. 2, pp. 163-180, 2006.

[15] DIMECC S4Fleet. (2016). Service Solutions for Fleet management - program [Online] Avaiable: http:// www.dimecc.com/dimecc-services/s4fleet/

[16] S. Kunttu, T. Ahonen, H. Kortelainen, and E. Jantunen, "Data to decision knowledge-intensive services for asset owners", in Proc. of EuroMaintenance 2016, to be published. 